УДК 343.131

\title{
АКТУАЛЬНЫЕ ПРОБЛЕМЫ РЕАЛИЗАЦИИ ТАЙНЫ ПЕРЕПИСКИ, ТЕЛЕФОННЫХ И ИНЫХ ПЕРЕГОВОРОВ, ПОЧТОВЫХ, ТЕЛЕГРАФНЫХ И ИНЫХ СООБЩЕНИЙ В УСЛОВИЯХ СОВРЕМЕННОГО ОБЩЕСТВА
}

\author{
Федюнина Елена Валерьевна \\ Научный руководитель: Перетятько Наталья Михайловна \\ к.ю.н., доцент \\ ФГБОУ ВО «Саратовская Государственная Юридическая Академия»
}

Аннотация: Статья посвящена исследованию актуальных проблем реализации тайны переписки, телефонных и иных переговоров, почтовых, телеграфных и иных сообщений в условиях современного общества. Автором рассматривается возникающие на практике вопросы воплощения права на тайну корреспонденции. Анализируется действующее законодательство и предлагаются пути решения сложившейся ситуации.

Ключевые слова: тайна корреспонденции, актуальные проблемы, конституция, уголовный процесс, принцип.

\section{ACTUAL PROBLEMS OF IMPLEMENTING THE SECRECY OF CORRESPONDENCE, TELEPHONE AND OTHER NEGOTIATIONS, POSTAL, TELEGRAPH AND OTHER MESSAGES IN THE CONDITIONS OF MODERN SOCIETY}

Fedyunina Elena Valeryevna Scientific adviser: Peretyatko Natalia Mikhailovna

\begin{abstract}
Article is devoted to the study of actual problems of implementing the secrecy of correspondence, telephone and other negotiations, postal, Telegraph and other messages in the conditions of modern society. The authors consider the issues that arise in practice in the implementation of the right to secrecy of correspondence. The current legislation is analyzed and ways to solve the current situation are proposed.
\end{abstract}




\section{ВСЕРОССИЙСКИЙ ИССЛЕДОВАТЕЛЬСКИЙ ФОРУМ

Key words: correspondence secrecy, current issues, constitution, criminal procedure, principle.

Часть 2 статья 23 Конституции РФ [1] провозглашает право каждого на тайну переписки, телефонных переговоров, почтовых, телеграфных и иных сообщений (далее - тайна корреспонденции). При этом основной закон допускает ограничение этого права на основании судебного решения. Тайна корреспонденции - важнейшее незыблемое начало реализации права человека на личную неприкосновенность, естественное и неотъемлемое право личности, признаваемое на международном уровне [2].

Согласно ст. 2 Конституции РФ человек, принадлежащие ему права и свободы, являются высшей ценностью, признание, соблюдение и защита человека, его прав и свобод - обязанность государства. Следовательно, государство обязано прикладывать максимум усилий для обеспечения законности, единства, обоснованности действий правоприменителя при реализации конституционных положений. Анализ же судебной практики показывает, что реализация тайны корреспонденции представлена неоднозначным толкованием нормы, переносом границы между противоправным и правомерным, предоставлением больших творческих возможностей субъектам правоприменения и т.д. Проблеме соблюдения тайны корреспонденции большое внимание уделено в науке [3] и общественности, что подтверждается острым обсуждением принципа тайны корреспонденции в СМИ [4]. Констатируется, что особенность статуса принципа тайны корреспонденции обуславливает необходимость его законодательной регламентации, конкретизации и разъяснения на законодательном уровне в целях соблюдения прав и свобод человека, во избежание двусмысленного толкования и произвольного правоприменения.

Прежде чем анализировать проблемы реализации принципа на современном этапе, необходимо отметить важные исторические аспекты в становлении принципа тайны корреспонденции в России. История развития тайны переписки, телефонных и иных переговоров, почтовых, телеграфных и иных сообщений в России характеризуется яркими событиями XIX века. Так в 1826 году по указу Николая I создан высший орган политического сыска в России - третье отделение собственной его императорского величества канцелярии. Основной функцией органа являлось осуществление охраны государственного строя, надзора и контроля над деятельностью 


\section{ВСЕРОССИЙСКИЙ ИССЛЕДОВАТЕЛЬСКИЙ ФОРУМ СТУДЕНТОВ И УЧАЩИХСЯ}

государственного аппарата и выборных учреждений. Безусловно, такое введение нельзя назвать позитивным шагом в сторону обеспечения прав человека, но и курс развития государства, заложенный императором, был иной, не во благо частных интересов: «...политика угнетения - угнетение систематическое, обдуманное «...», которая распространялась и на частную жизнь народа, на его мысль, его совесть «...». Отсюда в исходе его царствования всеобщее оцепенение умов, глубокая деморализация всех разрядов чиновничества, безвыходная инертность народа в целом.» [5, с.10]. Подтверждение слов А.Ф. Тютчевой можно найти в литературной мысли Н.В. Гоголя, который в «Ревизоре» высмеивал возможность почтмейстера всякое письмо вскрыть и прочитать, даже не то чтобы из предосторожности, а из любопытства [6, с. 17]. А.С. Пушкин, обращаясь к супруге, писал, что «...мысль, что кто-нибудь подслушивает нас, приводит меня в бешенство... Без политической свободы жить очень сложно; без семейственной неприкосновенности невозможно: каторга не в пример лучше» [7, с. 266]. Как отмечает Е.В. Киричек, события 1917 г. и дальнейший ход истории не оказал существенного влияния на правовое регулирование прав граждан на тайну переписки, лишь усугубив положение дел путем создания «мощной конспиративной системы тотального сбора политической информации [8, c.13-22].

В дальнейшем принцип тайны переписки, телефонных и иных переговоров, почтовых, телеграфных и иных сообщений перешел в разряд конституционных, особо значимых элементов статуса личности, хотя еще и не ставших основой конституционного строя. Так в Конституции СССР 1936 года данный принцип нашел отражение в ст. 128: «...тайна переписки охраняется законом» [9], в Конституции СССР 1977 года в ст. 56: «...тайна переписки охраняется законом» [10].

Однако возведенный в «конституционный ранг» принцип тайны корреспонденции, поставленный на службу обеспечения целостности и незыблемости прав личности, провозглашающий признание прав и свобод человека важнейшими ценностями, продолжал нарушаться.

Так С.Д. Довлатов в рубрике «Переслушивая свободу» (1989 г.) отзывается о разговоре с работником почты: «...к нам раз в неделю примерно заходит товарищ из органов, и мы ему вашу корреспонденцию откладываем, он всю изучает, а какие-то письма уносит с собой". Я спросил: "Это со мной одним такая история?". "Нет, - говорит, - у нас таких шестеро или семеро"» [11]. 


\section{ВСЕРОССИЙСКИЙ ИССЛЕДОВАТЕЛЬСКИЙ ФОРУМ

В настоящее время право на тайну переписки помимо конституционного закрепления «внедрилось» в ряд нормативных актов. В ч.1 ст. 13 УПК РФ сказано, что ограничить права человека на тайну переписки, телефонных и иных переговоров, а также телеграфных, почтовых и других сообщений допускается только на основании решения суда [12]. В ч. 2 ст. 13 УПК РФ законодатель закрепляет, что наложение ареста на телеграфные и почтовые отправления, равно как и выемка таких отправлений в учреждениях связи, запись и контроль телефонных и иных переговоров, получение информации о соединениях между абонентами и (или) абонентскими устройствами могут быть произведены также только на основании решения суда.

В статье 15 Ф3 от 17.07.1999 № 176-Ф3 «О почтовой связи» [13] говорится о том, что тайна телеграфных, почтовых и иных сообщений, которые входят в сферу деятельности операторов почтовой связи, равно как и тайна переписки, гарантируется государством. В ст. 8 Ф3 от 12.08.1995 № 144-Ф3 «Об оперативно-розыскной деятельности» [14], в Ф3 от 7.07.2003 г. № 126-Ф3 «О связи» [15], а также в Правилах оказания услуг почтовой связи, утвержденных Приказом Минкомсвязи России от 31.07.2014 № 234 (ред. от 27.03.2019) [16] отмечается, что на территории Российского государства каждому гарантируется тайна переписки, почтовых отправлений и телефонных переговоров, а также телеграфных и других сообщений.

Нарушение права на тайну корреспонденции является преступлением и влечет уголовную ответственность по ст. 138 УК РФ [17]. В чём же выражается данное нарушение? Противоправность деяния как указывает А.И. Рарог $[18$, c. 440], выражается в таких действиях как «...ознакомление с почтовотелеграфной или радиокорреспонденцией или иными сообщениями граждан (без их на то согласия), прослушивание телефонных переговоров, а также в разглашении содержания такой корреспонденции, переговоров и сообщений при отсутствии судебного решения».

Пункт 4 ПП ВС РФ от 28.12.2018 г. № 46 «О некоторых вопросах судебной практики по делам о преступлениях против конституционных прав и свобод человека и гражданина (статьи 137, 138, 138.1, 139, 144.1, 145, 145.1 Уголовного кодекса Российской Федерации)» [19] устанавливает рекомендации для судов в целях единообразной практики применения законодательства: «...судам следует иметь ввиду, что тайна переписки «...», признается нарушенной, когда: 


\section{ВСЕРОССИЙСКИЙ ИССЛЕДОВАТЕЛЬСКИЙ ФОРУМ

1. Доступ к переписке «...» совершен без согласия лица, чью тайну она составляет при отсутствии законных оснований для ограничения конституционного права граждан на тайну переписки «...».

2. Доступ к переписке «...» осуществлен при отсутствии законных оснований для ограничения конституционного права граждан на тайну переписки «...».

3. Осуществлен незаконный доступ к информации о входящих и об исходящих сигналах соединения между абонентами или абонентскими устройствами пользователей связи (дате, времени, продолжительности соединений, номерах абонентов, других данных, позволяющих идентифицировать абонентов).

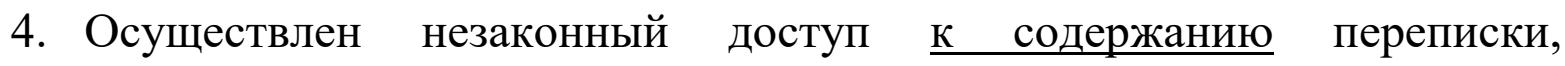
переговоров, сообщений может состоять в ознакомлении с текстом и (или) материалами переписки, сообщений, прослушивании телефонных переговоров, звуковых сообщений, их копировании, записывании с помощью различных технических устройств и т.П.»

Полагаем, что в данных положениях имеется неопределенность: всегда ли при согласии лица, чью тайну составляет переписка «...» необходимо судебное решение? С одной стороны - да, так как ст. 13 УПК РФ предусматривает ограничение права на тайну переписки только на основании судебного решения, а с другой стороны в судебной практике предусматривается вариативность: достаточно согласия лица, чью тайну составляет переписка, либо судебного решения, однако, всё же полагается, что такое толкование суда противоречит федеральному закону.

Сложность соблюдения тайны корреспонденции возникает также по причине отсутствия законодательного закрепления положений, обосновывающих необходимость вынесения судебного решения. На помощь приходит устоявшаяся практика правоприменения. Так Европейский суд по правам человека устанавливает два необходимых критерия принятия судом решения, допускающего умаление принципа тайны корреспонденции [20, с. $602-609$, с. $182-195]$ :

1. Реальность конфликта частного интереса сохранения тайны корреспонденции и более значимых публичных интересов государства (государственная, общественная безопасность, экономическая безопасность государства, предотвращение беспорядков, преступлений, охраны здоровья или нравственности, защита прав и свобод других лиц. 


\section{ВСЕРОССИЙСКИЙ ИССЛЕДОВАТЕЛЬСКИЙ ФОРУМ СТУДЕНТОВ И УЧАЩИХСЯ}

2. «Необходимость» и «временность» вмешательства, то есть в каждом случае необходимо наличие доказанного факта о том, что без нарушения права на тайну корреспонденции вред защищаемым публичным интересам будет неминуемым.

Однако анализ определения Конституционного суда «Об отказе в принятии к рассмотрению жалобы гражданина Попова А.А. на нарушение его конституционных прав частью третьей статьи 389.2 УПК РФ» свидетельствует о том, что Конституционный суд РФ прокладывает собственный путь реализации права на тайну корреспонденции. Так суд отказал в принятии жалобы А.Н. Попова на нарушение его конституционных прав статьями 176 и 177 УПК РФ. В обосновании позиции суд указал, что «...в ходе осмотра принадлежащего заявителю сотового телефона он сообщил установленный на нем пароль, выразил готовность представить распечатку телефонных соединений с используемого им номера, не возражал против исследования имеющихся в телефоне сообщений и сведений о телефонных соединениях»[21]. Сопоставляя действия Конституционного суда РФ с рассматриваемым выше ПП ВС РФ [22], отказ в принятии жалобы правомерен, так как существует согласие лица, чью тайну составляет корреспонденция. Однако, как нами отмечалось ранее, такая практика противоречит нормам УПК РФ.

В другом постановлении Конституционный суд РФ в обоснование своего определения указал, что «проведение осмотра и экспертизы с целью получения имеющей значение для уголовного дела информации, находящейся в электронной памяти абонентских устройств, изъятых при производстве следственных действий в установленном законом порядке, не предполагает вынесения об этом специального судебного решения» [23]. В представленном случае действия Конституционного суда РФ идут вразрез не только с нормами законодательства, но и представляет совершенно иную, собственную незафиксированную в Постановлении Пленума ВС РФ позицию. Но, с другой стороны, высшая судебная инстанция дает только рекомендации для судов, о чем говорит формулировка « ...судам следует иметь в виду», следовательно, каждый судья руководствуется при вынесении постановления, в том числе и собственными убеждениями при вынесении постановления.

Однако на практике встречаются и иные случаи. Так следователем в отсутствии судебного решения был изъят телефон, принадлежащий подозреваемому по уголовному делу, и в дальнейшем произведен осмотр доказательств, в частности изучены смс-сообщения, а также список контактов. 


\section{ВСЕРОССИЙСКИЙ ИССЛЕДОВАТЕЛЬСКИЙ ФОРУМ СТУДЕНТОВ И УЧАЩИХСЯ}

Постановлением №3.10-11/12 от 04.07.2012 г. Советским районным судом г. Омска действия следователя признаны законными, так как имелись предусмотренные законом основания для изъятия телефона. А действия по просмотру информации на носителе признаны незаконными ввиду отсутствия судебного решения. Обязанность следователя получать судебное решение на осмотр тайны переписки «...» обусловлена ст. 8 Конвенции о защите прав человека и основных свобод - право каждого на уважение его личной и семейной жизни «...»[24].

Кировский районный суд г. Саратова удовлетворил аналогичную жалобу, но основаниями для признания действий следователя незаконными стало признание нарушения конституционных прав собственности на имущество [25].

Следовательно, даже в «положительной» практике, где действия лиц, приводящие к нарушению тайны корреспонденции, признаны незаконными по причине отсутствия судебного решения, суд использует различную аргументацию своих постановлений, что также свидетельствует о наличии пробелов в законодательстве.

Решение проблемы обеспечения тайны переписки возможно только на законодательном уровне. Исторический анализ показал, что умаление, несоблюдение данного принципа сразу же получает бурную негативную реакцию общественности, является незаконным средством контроля и надзора за частной жизнью. В современном российском обществе нет органов политического сыска, давно изменен вектор развития государства, признание прав и свобод человека высшей ценностью провозглашено основой конституционного строя, то есть фактически созданы все условия и предпосылки для полного обеспечения тайны корреспонденции, однако на практике выявляется множество сложностей. Причина данных проблем видится в отсутствии законодательного закрепления положений, обосновывающих необходимость вынесения судебного решения, в отсутствии законодательного закрепления положений, свидетельствующих о нарушении принципа тайны корреспонденции, в противоречии опубликованной судебной практике по некоторым вопросам реализации права на тайну корреспонденции Верховного суда РФ федеральному законодательству.

Следовательно, для устранения выявленных проблем, законодателю необходимо закрепить случаи необходимости принятия решения судом на производство процессуальных действий, способных повлечь умаление тайны 


\section{ВСЕРОССИЙСКИЙ ИССЛЕДОВАТЕЛЬСКИЙ ФОРУМ

корреспонденции. Законодателю необходимо также чётко установить, что является нарушением тайны корреспонденции путём конкретного закрытого перечня случаев, во избежание двусмысленного толкования и произвольного правоприменения в целях соблюдения прав и свобод человека и гражданина и признания их высшей ценностью.

\section{Список литературы}

1. Конституция Российской Федерации (принята всенародным голосованием 12.12.1993 с изменениями, одобренными в ходе общероссийского голосования 01.07.2020).

2. См. ст. 12 "Всеобщая декларация прав человека" (принята Генеральной Ассамблеей ООН 10.12.1948); ч. 1 ст. 17 Международный пакт о гражданских и политических правах" (Принят 16.12.1966 Резолюцией 2200 (XXI) на 1496-ом пленарном заседании Генеральной Ассамблеи ООН); ст. 1 "Конвенция о защите физических лиц при автоматизированной обработке персональных данных" (Заключена в г. Страсбурге 28.01.1981) (вместе с Поправками к Конвенции о защите физических лиц при автоматизированной обработке персональных данных (СДСЕ N 108), позволяющими присоединение европейских сообществ, принятыми Комитетом Министров в Страсбурге 15.06.1999).

3. См. Результаты поискового запроса «тайна переписки» за 2019-2020 годы, в научной электронной библиотеке «Elibrary.ru» за 2019-2020 годы URL: https://www.elibrary.ru/query_results.asp (дата обращения: 31.10.2020)

4. См. Газета "Коммерсанть" №196/П от 26.10.2020, стр. 7; См. Сетевое издание «Комсомольская правда в Тамбове» URL: https://www.tambov. kp.ru/online/news/4068269/ (Дата обращения: 7.11.2020); Российское информационное агентство «Live24» URL: https://live24.ru/v-strane/30583-kpersonalnym-dannym-nashli-innovacionnyj-podhod.html (Дата обращения: 07.11.2020); Информационное агентство «Znak» URL: https://www. znak.com/2020-11-06/v_tyumeni_sledovatel_poluchil_dva_goda__uslovno_za _poddelku_ulik_po_delu_o_perepiske_v_vk (Дата обращения: 7.11.2020)

5. Цит. по Тютчевой А.Ф. «При дворе двух императоров» (Воспоминания и фрагменты дневников фрейлины двора Николая I и Александра II) 49 c. URL: https://www.litmir.me/br/?b=242653\&p=48 (Дата обращения: 08.11.2020) 


\section{ВСЕРОССИЙСКИЙ ИССЛЕДОВАТЕЛЬСКИЙ ФОРУМ

6. Цит. по Гоголь Н.В. Ревизор // Гоголь Н.В. Полное собрание сочинений: [В 14 т.]/ АН СССР, 1937-1952 Т.4. Ревизор - 1951. 95 с.

7. Русскій біографическій словарь. Томъ XV. Притвицъ - Рейсъ Тип. Императорской Академии Наук СПб, 1910 г. 560 с.

8. Цит. по Киричёк Е.В. Становление и развитие прав и свобод человека и гражданина: философско-правовое измерение / Е.В. Киричёк // Юридическая наука и правоохранительная практика. - 2011. - №2 (16). - С. 13-22

9. Конституция (основной закон) Союза Советских Социалистических Республик Утверждена Чрезвычайным VIII съездом Советов Союза CCP 5 декабря 1936 года//Советская сибирь. - 1936 г - № 283 (5143). - С. 2-4.

10. Конституция (Основной Закон) Союза Советских Социалистических Республик Принята на внеочередной седьмой сессии Верховного Совета СССР девятого созыва 7 октября 1977 года. М. : Политиздат, 1977. - 127 с.

11. Цит. по программе из цикла «Переслушивая Свободу» запись весны 1989 года.

12. Уголовно-процессуальный кодекс от 18.12.2001 N 174-Ф3 (ред. 27.10.2020) // Собрание законодательства РФ. 2001. N 52 (ч. I). Ст. 4921.

13. Федеральный закон от 17.07.1999 № 176-ФЗ «О почтовой связи» (ред.29.06.2018) //Собрание законодательства РФ. 1999. №29. Ст. 3697

14. Федеральный закон от 12.08.1995 № 144-Ф3 «Об оперативнорозыскной деятельности» // Собрание законодательства РФ. 1995. №33. Ст. 3349 .

15. Федеральный закон от 07.07.2003 № 126-Ф3 «О связи»// Собрание законодательства РФ. 2003. №28. Ст. 2895.

16. Приказ Министерства связи и массовых коммуникаций Российской Федерации (Минкомсвязь России) от 31.07. 2014 N 234 г. «Об утверждении Правил оказания услуг почтовой связи» // URL : https://rg.ru/2014/12/31/pochtadok.html (Дата обращения: 08.11.2020)

17. Уголовный кодекс Российской Федерации от 13.06.1996 N 63-Ф3 (ред. от 21.10.2020) // Собрание законодательства РФ. 1996. № 25 Ст. 2954.

18. Уголовное право России. Части Общая и Особенная: учебник/ под ред. А. И. Рарога. - 10-е изд., перераб и доп. - М: Проспект, 2019, С.440.

19. Постановление Пленума Верховного Суда Российской Федерации от 25.12. 2018 N 46 г. «О некоторых вопросах судебной практики по делам о преступлениях против конституционных прав и свобод человека и гражданина (статьи 137, 138, 1381, 139, 1441, 145, 1451 Уголовного кодекса Российской 


\section{ВСЕРОССИЙСКИЙ ИССЛЕДОВАТЕЛЬСКИЙ ФОРУМ

Федерации)» URL: https://rg.ru/2019/01/09/vs-rf-46-dok.html (Дата обращения: 08.11.2020).

20. Klaas E others v.Germany. Судебное решение от 6 сентября 1978 г.// Европейский суд по правам человека. Избранные решения. Т.1 М.,2000 С.602609; Goodwin v United Kingdom. Судебное решение от 27 марта 1996 года. // Европейский суд по правам человека. Избранные решения Т.2 М., 2000. С.182195

21. Определение Конституционного Суда РФ от 24.04.2018 г. N 889-О «Об отказе в принятии к рассмотрению жалобы гражданина Попова Андрея Алексеевича на нарушение его конституционных прав частью третьей статьи 389.2 Уголовно-процессуального кодекса Российской Федерации» URL: http://base.garant.ru/71952544/\#friends (Дата обращения: 08.11.2020)

22. Постановление Пленума Верховного Суда Российской Федерации от 25.12. 2018 г. N 46 г. «О некоторых вопросах судебной практики по делам о преступлениях против конституционных прав и свобод человека и гражданина (статьи 137, 138, 1381, 139, 1441, 145, 1451 Уголовного кодекса Российской Федерации)» URL: https://rg.ru/2019/01/09/vs-rf-46-dok.html (Дата обращения: 08.11.2020)..

23. Определение Конституционного Суда РФ от 25.01.2018 N 189-О «Об отказе в принятии к рассмотрению жалобы гражданина Прозоровского Дмитрия Александровича на нарушение его конституционных прав статьями 176, 177 и 195 Уголовно-процессуального кодекса Российской Федерации» URL: https://legalacts.ru/sud/opredelenie-konstitutsionnogo-suda-rf-ot-25012018-n189-о/ (Дата обращения: 08.11.2020)

24. Уголовное дело № 264908. Постановление Советского районного суда г. Омска № 3.10-11/2012 от 04.07.2012 г. // Архив Советского районного суда г. Омска за 2012 год.

25. Апелляционное определение от 24 июля 2013 года г. Саратов URL: http://www.samosud.org/case_304821083 (Дата обращения: 29.10.2020).

(C) Е. В. Федюнина, 2020 